\title{
Accuracy of velocities from repeated GPS measurements
}

\author{
V. Akarsu ${ }^{1}$, D. U. Sanli ${ }^{2}$, and E. Arslan ${ }^{3}$ \\ ${ }^{1}$ Department of Architecture and Urban Planning, Zonguldak Vocational High School, Bulent Ecevit University, \\ Zonguldak, Turkey \\ ${ }^{2}$ Department of Geomatic Engineering, Civil Engineering Faculty, Yildiz Technical University, Istanbul, Turkey \\ ${ }^{3}$ Department of Geomatics Engineering, Civil Engineering Faculty, Istanbul Technical University, Istanbul, Turkey
}

Correspondence to: D. U. Sanli (usanli@yildiz.edu.tr)

Received: 20 October 2012 - Revised: 18 January 2015 - Accepted: 5 April 2015 - Published: 21 April 2015

\begin{abstract}
Today repeated GPS measurements are still in use, because we cannot always employ GPS permanent stations due to a variety of limitations. One area of study that uses velocities/deformation rates from repeated GPS measurements is the monitoring of crustal motion. This paper discusses the quality of the velocities derived using repeated GPS measurements for the aim of monitoring crustal motion. From a global network of International GNSS Service (IGS) stations, we processed GPS measurements repeated monthly and annually spanning nearly 15 years and estimated GPS velocities for GPS baseline components latitude, longitude and ellipsoidal height. We used web-based GIPSY for the processing. Assuming true deformation rates can only be determined from the solutions of $24 \mathrm{~h}$ observation sessions, we evaluated the accuracy of the deformation rates from 8 and $12 \mathrm{~h}$ sessions. We used statistical hypothesis testing to assess the velocities derived from short observation sessions. In addition, as an alternative control method we checked the accuracy of GPS solutions from short observation sessions against those of $24 \mathrm{~h}$ sessions referring to statistical criteria that measure the accuracy of regression models. Results indicate that the velocities of the vertical component are completely affected when repeated GPS measurements are used. The results also reveal that only about $30 \%$ of the $8 \mathrm{~h}$ solutions and about $40 \%$ of $12 \mathrm{~h}$ solutions for the horizontal coordinates are acceptable for velocity estimation. The situation is much worse for the vertical component in which none of the solutions from campaign measurements are acceptable for obtaining reliable deformation rates.
\end{abstract}

\section{Introduction}

Today GPS is widely used to monitor crustal motion. Methods of continuous GPS have been well established for this purpose (Mao et al., 1999; Williams et al., 2004; AmiriSimkooei et al., 2007) and are routinely used for monitoring tectonic motion. Researchers are also studying real-time continuous GPS and high-rate GPS from the frequencies of 1 to $50 \mathrm{~Hz}$ GPS for the same purpose (Genrich and Bock, 2006; Blewitt et al., 2006, 2009; Larson, 2009; Avallone et al., 2011; Crowell et al., 2012). Such studies aim to use the results for the early prediction of earthquakes, tsunamis and other natural hazards of similar character.

Static GPS measurements have been the tradition for resolving large crustal motion. However, recently scientists have been working on improving the quality of real-time measurements and rapid static GPS based on continuously operating reference stations (Crowell et al., 2012; Hastaoglu and Sanli, 2011; Wang and Soler, 2012). The accuracy of static GPS measurements has been documented well. Researchers have studied the effect of observing session duration, baseline length and the network of reference stations on the accuracy of the static GPS (Eckl et al., 2001; Soler et al., 2006; Sanli and Engin, 2009; Firuzabadì and King, 2012).

Repeated static GPS measurements (also known as GPS campaigns or episodic GPS), which were the desired methods in crustal motion monitoring starting from the end of 1980s, are still in use due especially to financial limitations and various other constraints. Ideal observation session length for a GPS campaign is $24 \mathrm{~h}$. Additionally, carrying out repeated GPS measurements in three different sessions over 3 consecutive days is desired. However, depending on the field work limitations, repeated GPS measurements are 
sometimes performed with only one session usually lasting $6 \mathrm{~h}$ through $12 \mathrm{~h}$. In the literature, it is possible to come across many crustal deformation experiments performed in this way (Miranda et al., 2012; Elliot et al., 2010; Rontogianni et al., 2010; Ashurkov et al., 2011; Ozener et al., 2012; Tran et al., 2012; Catalão et al., 2011).

Time series characteristics of continuous GPS solutions and the quality of velocities estimated from long GPS time series have been studied in detail (Williams, 2003; AmiriSimkooei et al., 2007; Santamaría-Gómez et al., 2011). The accuracy of GPS static positioning has also been reported thoroughly; however, investigations on the accuracies of static GPS velocities from repeated measurements have not been carried out yet (Eckl et al., 2001; Soler et al., 2006; Sanli and Engin, 2009; Firuzabadì and King, 2012). While bringing rapid static GPS solutions into conformity with static GPS solutions, Hastaoglu and Sanli (2011) noticed that the accuracy of GPS velocities from the repeated measurements is highly correlated with the observing session duration.

In this study, using the continuous data of International GNSS Service (IGS) stations archived by the Scripps Orbit and Permanent Array Center (SOPAC) we studied the accuracy of static GPS velocities from the repeated campaign measurements. The $24 \mathrm{~h}$ IGS data were segmented into shorter sessions (i.e., 8 and $12 \mathrm{~h}$ ) to create the GPS campaigns, and GPS positions were computed for these subsegmented campaigns. Position time series were formed for all three GPS baseline latitude, longitude and ellipsoidal height using data from the repeated GPS campaigns, which were prepared as explained in the above. The GPS velocities computed from the short GPS campaigns for all three baseline components were then compared with the velocities computed from $24 \mathrm{~h}$ data. Based on various statistical methods, conclusions were drawn on the quality of the velocities derived from campaign measurements which are still in use today for monitoring crustal deformation.

\section{Analysis of GPS data}

GPS data were obtained from IGS through SOPAC archives at http://sopac.ucsd.edu/ as described in Ozturk and Sanli (2011). The permanent GPS stations used throughout the study are shown in Fig. 1. GPS data were obtained in Receiver Independent Exchange (RINEX) format and sampled with $7.5^{\circ}$ elevation cutoff angle and $30 \mathrm{~s}$ recording intervals. Jet Propulsion Laboratory (JPL) final precise orbits and clocks were used in the analysis.

The Automatic Precise Positioning Service (APPS) was used to process the GPS data. APPS is implemented by the Global Differential GPS System of NASA's JPL (http:// apps.gdgps.net). It employs GIPSY/OASIS software's "precise point positioning" (PPP) developed by Zumberge et al. (1997). GIPSY utilizes precise satellite orbit and clock

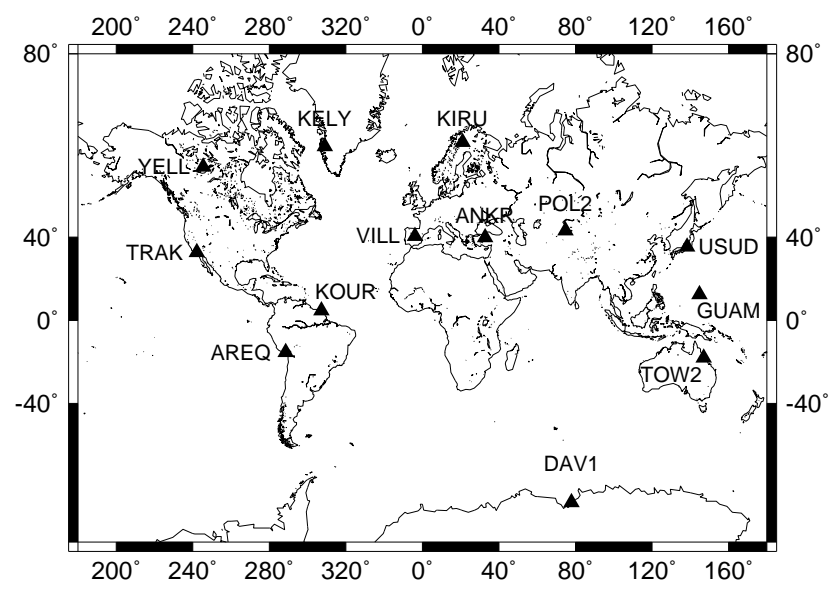

Figure 1. IGS permanent GPS stations used in the study.

data from a global network solution (i.e., JPL "final" precise orbit determination). The results were represented using the International Earth Rotation Service's reference system ITRS (Petit and Luzum, 2010), as realized through the reference frame ITRF2005 (Altamimi et al., 2007). Tropospheric zenith wet delay was modeled as a random-walk parameter with variance of $3 \mathrm{~mm}^{2}$ per hour. The dry troposphere was modeled using a global mapping function (Boehm et al., 2006). The ionospheric delay was eliminated from the $L_{1}$ and $\mathrm{L}_{2}$ data combination using both pseudo-range and carrier phase observations. Second-order ionospheric correction was applied using the model of Kedar et al. (2003). Satellite and receiver antenna phase center variation maps were automatically applied following IGS standards.

A total of 13 IGS sites distributed widely around the globe were selected for the analysis (Fig. 1). We applied two different analysis strategies. First, for each site we selected around 15 days of data observed each year in January from the years 1995 to 2010 inclusive. This was to assess the GPS campaigns that are performed traditionally. Namely, GPS data are collected 1 day per year, usually over 6 to $10 \mathrm{~h}$, and the campaigns are continued for a few years. Secondly, we sampled the data (i.e., densified the time series), taking 1 day from each month of the year corresponding to January, again spanning about 15 years. This was actually to take into account the seasonal variation due to annual and semiannual terms in the vertical component (Blewitt and Lavalleé, 2002). Obviously this would not be achieved with annually sampled data.

Each day's data were subdivided into mutually nonoverlapping sessions for each of 8 and $12 \mathrm{~h}$ values of the observing session. For each subset of data, we computed the positional coordinates using the PPP method described above. For each day and each unknown point, a position was computed for each $24 \mathrm{~h}$ session. The position from each day's $24 \mathrm{~h}$ sessions was then adopted as the "true" position of the point. For the monthly and annually sampled data spanning 
1995 through 2010, true position time series for the geodetic coordinates latitude, longitude and ellipsoidal height (i.e., $\phi$, $\lambda$ and $h$ ) were formed from $24 \mathrm{~h}$ solutions. The velocities estimated from $24 \mathrm{~h}$ solution time series were accepted as the truth, and these were compared with the velocities obtained from the short, segmented (i.e., 8 and $12 \mathrm{~h}$ ) solution time series. These velocities form the basis for the statistics presented throughout this paper.

\section{Evaluation procedure}

In this section we describe our analysis procedure for the site KIRU using the annually sampled GPS campaigns, and in the following section we present results and discussions for all 13 sites following the same procedure. Figure 2 depicts the comparison of 8 and $24 \mathrm{~h}$ position time series for three GPS baseline components: latitude, longitude and ellipsoidal height.

In Fig. 2, the black discrete line connected through a black diamond indicates the variation with time from $24 \mathrm{~h}$ measurements. The variations of $0-8,8-16$ and $16-24 \mathrm{~h}$ are superimposed onto the variation of the $24 \mathrm{~h}$. Note that for latitude and longitude the variation from sub-segmented $8 \mathrm{~h}$ solutions align well with the variation from $24 \mathrm{~h}$. The difference of the deformation rates for the longitude values is only slightly worse than those of the latitude values. This is also the case for the $R^{2}$ values. The variation for the horizontal coordinates is almost linear, clearly showing the tectonic motion of the station. To model the linear variation we used

$x_{i}=a t_{i}+b+v_{i}$,

where $x_{i}$ designates any coordinate value, $a$ the velocity (i.e., deformation rate), $b$ the intercept, $t_{i}$ the time and $v_{i}$ residuals. Stations such as ANKR and AREQ contain offsets due to earthquakes. Thus, to account for the offsets in the data we expand Eq. (1) as

$x_{i}=a t_{i}+b+o_{i} x_{\mathrm{off}}+v_{i}$,

where $o_{i}$ is the offset coefficient and $x_{\text {off }}$ is the offset magnitude.

However, the height component deviations of short sessions in comparison to $24 \mathrm{~h}$ solutions are greater. In order to provide a clearer presentation we prepared Table 1 .

In Table 1, we compare crustal motion and $R^{2}$ values from 8 and $24 \mathrm{~h}$ solutions for latitude, longitude and height. The statistical tool $R^{2}$ is used in regression analysis as a measure of fit of the regression line for pairs of variables. $R^{2}$, i.e., the "coefficient of determination", for any coordinate $x$ is given by

$$
R^{2}=1-\frac{\sum_{i=1}^{n} \hat{v}_{i}^{2}}{\sum_{i=1}^{n}\left(x_{i}-\bar{x}\right)^{2}}=1-\frac{\sum_{i=1}^{n}\left(x_{i}-\hat{x}_{i}\right)^{2}}{\sum_{i=1}^{n}\left(x_{i}-\bar{x}\right)^{2}},
$$
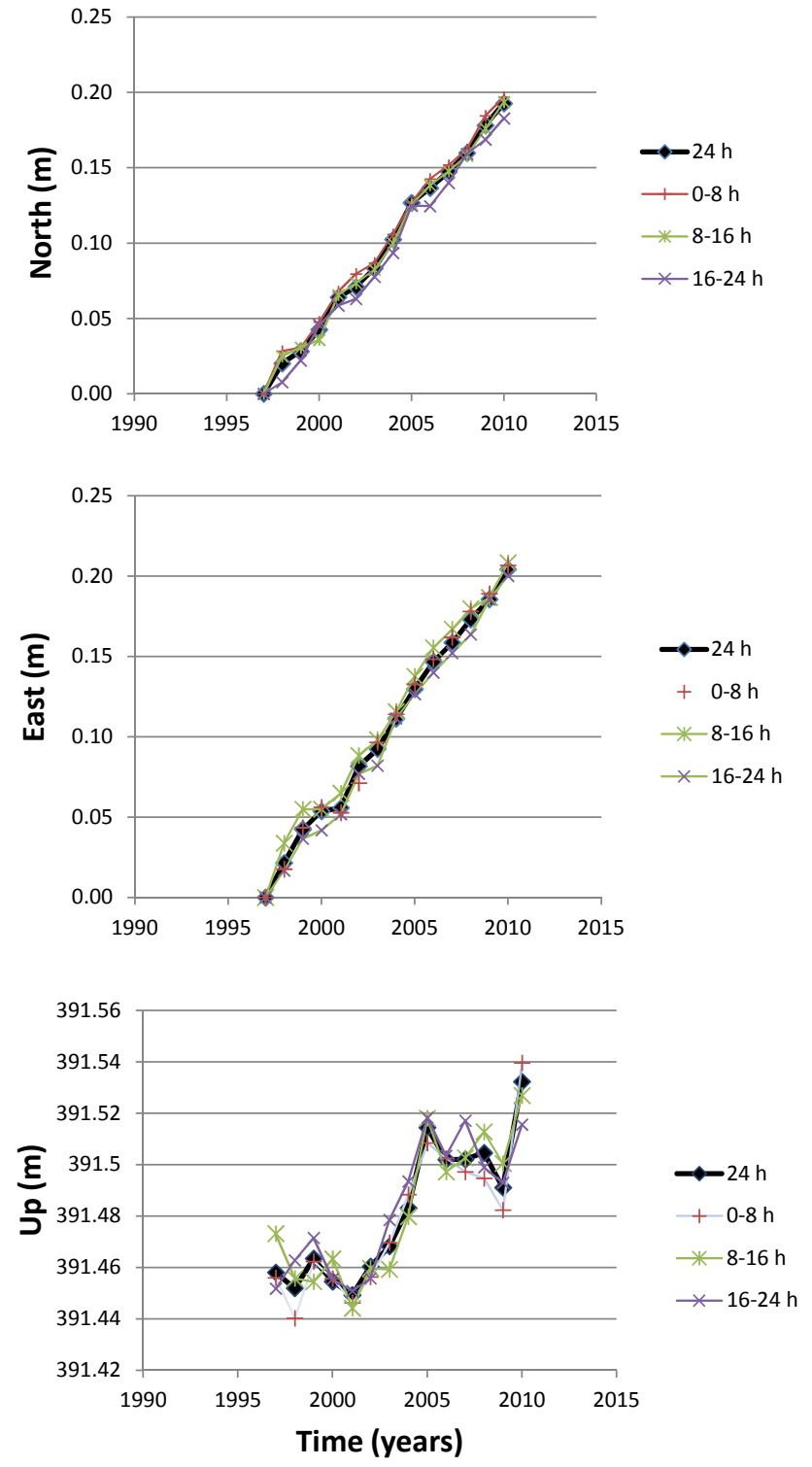

Figure 2. Comparison of the crustal motion using the results of short sessions and $24 \mathrm{~h}$ solutions for the station KIRU.

where $\bar{x}=\frac{1}{n} \sum_{i=1}^{n} x_{i}$ and $n$ denotes the number of measurements.

The residual $\hat{v}_{i}=x_{i}-\hat{x}_{i}$ refers to the regression values $\hat{x}_{i}=\hat{a} t_{i}+\hat{b}$ based on the least squares $\left(\sum_{i=1}^{n} v_{i}^{2}=\min \right)$ estimates $\hat{a}, \hat{b}$ in the observation model given by Eq. (1).

Note that for the horizontal components in Table $1, R^{2}$ values from latitude and longitude for $8 \mathrm{~h}$ evaluations are pretty close to those of $24 \mathrm{~h}$ solutions. $R^{2}$ values are usually at 0.99 levels, showing almost perfect linearity due to tectonic motion.

The crustal motion for the height component for KIRU from the annually sampled data is not clearly linear, and 
Table 1. Comparison of the $R^{2}$ values and deformation rates for all three GPS baselines from the station KIRU. $R^{2}$ values are obtained through the regression analysis of GPS solution time series.

\begin{tabular}{lrrrr}
\hline Coordinate time series & \multicolumn{4}{c}{$R^{2} /$ Velocity $\left(\mathrm{mm} \mathrm{yr}^{-1}\right)$} \\
\cline { 2 - 5 } & $24 \mathrm{~h}$ & $0-8 \mathrm{~h}$ & $8-16 \mathrm{~h}$ & $16-24 \mathrm{~h}$ \\
\hline Latitude & 0.9963 & 0.9950 & 0.9926 & 0.9927 \\
& 14.8 & 14.8 & 14.6 & 14.5 \\
\hline Longitude & 0.9954 & 0.9918 & 0.9890 & 0.9942 \\
& 15.4 & 15.8 & 15.2 & 15.4 \\
\hline Height & 0.7632 & 0.7145 & 0.6874 & 0.6933 \\
& 5.6 & 5.7 & 5.4 & 5.1 \\
\hline
\end{tabular}

hence $R^{2}$ values vary between 0.68 and 0.75 . This is because height time series can not only be explained with a linear variation. Blewitt and Lavalleé (2002) showed that GPS height time series also contain annual seasonal motion. The major annual motion is induced from hydrological and atmospheric loading. Later on, Williams et al. (2004) and AmiriSimkooei et al. (2007) included annual and semiannual motions in their analysis of continuous GPS time series. Santamaría Gómez et al. (2011) noticed seasonal variations in continuous GPS time series from smaller periods such as 3 and 4 months but obviously with decreasing amplitudes. For this reason, a linear model might not always fit well to height time series and one might encounter smaller $R^{2}$ values. Also note that, for the height component, the differences between the $R^{2} \mathrm{~s}$ of $8 \mathrm{~h}$ solutions and $24 \mathrm{~h}$ solutions become larger. In addition, the difference in the deformation rates when $24 \mathrm{~h}$ solutions are taken as the truth becomes worse for the height component. For this reason, as an additional remedy mainly to improve the findings of the vertical component, we densified the solution time series so that the series will include results from monthly spanned GPS data, and hence the seasonal motion due to annual and semiannual terms will be taken into account. Obviously, we further extended our observational model given with Eq. (2) into

$x_{i}=a t_{i}+b+o_{i} x_{\mathrm{off}}+\sum_{n=1}^{q}\left[c_{n} \cos \frac{2 \pi k t_{i}}{T_{n}}+d_{n} \sin \frac{2 \pi k t_{i}}{T_{n}}\right]+v_{i}$,

where $q=2, T_{1}=1$ year and $T_{2}=0.5$ year. Note that the repetition of the observations at the same date each year is quasi-periodic with modulated (time-dependent) coefficients.

In order to assess the velocities from 8 and $12 \mathrm{~h}$ solutions, we applied hypothesis testing to the velocity values $\hat{a}$ estimated from least squares analysis. First we tested whether or not unit variances, i.e., the unit variances from the least squares estimation analysis of $24 \mathrm{~h}$ and shorter spans, are equal. An $F$ test has been applied with the null hypothesis $H_{0}: \sigma_{024}^{2}=\sigma_{0 \mathrm{~s}}^{2}$ against the alternative hypothesis $H_{\mathrm{A}}$ : $\sigma_{024}^{2} \neq \sigma_{0 \mathrm{~s}}^{2}$, where $\sigma_{024}^{2}$ denotes the unit variances from $24 \mathrm{~h}$ sessions and $\sigma_{0 \mathrm{~s}}^{2}$ the unit variance from short GPS campaigns. Ensuring the unit variances are equal then we tested the zero hypotheses $H_{0}: \mu_{8}=\mu_{24}$ and $H_{0}: \mu_{12}=\mu_{24}$ against the alternative hypotheses $H_{\mathrm{A}}: \mu_{8} \neq \mu_{24}$ and $H_{\mathrm{A}}: \mu_{12} \neq \mu_{24}$. Here $\mu_{8}, \mu_{12}$ and $\mu_{24}$ correspond to the estimates $\hat{a}_{8}, \hat{a}_{12}$ and $\hat{a}_{24}$, respectively. Namely we tested whether the velocities obtained from 8 or $12 \mathrm{~h}$ solutions differ significantly from the velocities derived from $24 \mathrm{~h}$ solutions. Since horizontal components are under the effect of tectonic motion, which is linear in character, and one can observe this motion clearly from the annual time series (with $R^{2}$ values almost perfectly close to 1 ) of horizontal components, we did not refer to the results of monthly solutions for the evaluation of the velocities for horizontal GPS coordinates. Hence, we were also able to criticize the previous work that used annually repeated GPS campaigns. Since degree of freedom values from annual solutions were small varying between 10 and 13, we used Student's two-sided $t$ test for the horizontal components. The degree of freedom for the vertical component was around 160 , and hence a two-sided $z$ test was used for testing the velocities of the height component.

As an alternative statistical methodology, we formed root mean square differences (RMSDs) using $24 \mathrm{~h}$ solutions as the truth and compared those with root mean square error of the estimated coordinates (RMSEEs) derived from the regressions of individual short session solutions. The RMSD between the time series of $24 \mathrm{~h}$ solutions and those of the shorter data spans (i.e., 8 and $12 \mathrm{~h}$ ) can be formed with (Pan and Yin, 2012)

$\operatorname{RMSD}=\sqrt{\frac{\sum\left(x_{\mathrm{s}}-x_{24}\right)^{2}}{n}}$,

where $x_{24}$ denotes the random variable for GPS solutions using $24 \mathrm{~h}$ data, $x_{\mathrm{S}}$ denotes the random variable for solutions using short GPS observations such as 8 and $12 \mathrm{~h}$ and $n$ denotes number of measurements (i.e., solutions). RMSEE is a measure of the accuracy of predictions made with a regression line. Referring to Eqs. (1) through (3), RMSEE can be formed as (Brown, 1999)

$\mathrm{RMSEE}=\sqrt{\frac{\sum(x-\hat{x})^{2}}{n-2}}$

or

RMSEE $=S_{x} \sqrt{1-r^{2}} \sqrt{\frac{n}{n-2}}$,

where $r$ is the sample correlation (i.e., correlation between $x$ and $t$ in Eq. 1) and $S_{x}$ is the sample standard deviation of $x$.

\section{Results and discussion}

In Tables 2 through 4 we represent the statistical hypothesis testing results outlined in the previous section and the 
Table 2. Hypothesis testing results for latitude: rejections indicated in bold-faced letters are related to an $F$ test; rejections indicated in underlined bold-faced letters are from Student's $t$ test; the stations with $R^{2}$ values smaller than 0.99 are not used in the evaluation.

\begin{tabular}{|c|c|c|c|c|c|}
\hline Station & $R^{2}$ & $\begin{array}{l}8 \mathrm{~h} \\
\text { Test result }\end{array}$ & $R^{2}$ & $\begin{array}{l}12 \mathrm{~h} \\
\text { Test result }\end{array}$ & $\begin{array}{l}24 \mathrm{~h} \\
R^{2}\end{array}$ \\
\hline ANKR & $\begin{array}{l}0.9796 \\
0.9967 \\
0.9905\end{array}$ & $\begin{array}{l}H_{0} \text { rejected } \\
H_{0} \text { rejected } \\
H_{0} \text { rejected }\end{array}$ & $\begin{array}{l}0.9939 \\
0.9962\end{array}$ & $\begin{array}{l}H_{0} \text { rejected } \\
H_{0} \text { rejected }\end{array}$ & 0.9984 \\
\hline AREQ & $\begin{array}{l}0.9964 \\
0.9965 \\
0.9965\end{array}$ & $\begin{array}{l}H_{0} \text { accepted } \\
H_{0} \text { accepted } \\
H_{0} \text { accepted }\end{array}$ & $\begin{array}{l}0.9973 \\
0.9961\end{array}$ & $\begin{array}{l}H_{0} \text { accepted } \\
H_{0} \text { accepted }\end{array}$ & 0.9969 \\
\hline DAV1 & $\begin{array}{l}0.9863 \\
0.8892 \\
0.9464\end{array}$ & $\begin{array}{l}H_{0} \text { accepted } \\
\boldsymbol{H}_{0} \text { rejected } \\
\boldsymbol{H}_{\mathbf{0}} \text { rejected }\end{array}$ & $\begin{array}{l}0.9795 \\
0.9402\end{array}$ & $\frac{H_{0} \text { rejected }}{H_{0} \text { rejected }}$ & 0.9839 \\
\hline GUAM & $\begin{array}{l}0.5801 \\
0.5761 \\
0.7348\end{array}$ & $\begin{array}{l}\boldsymbol{H}_{\mathbf{0}} \text { rejected } \\
H_{0} \text { accepted } \\
H_{0} \text { accepted }\end{array}$ & $\begin{array}{l}0.6241 \\
0.6917\end{array}$ & $\begin{array}{c}\boldsymbol{H}_{\mathbf{0}} \text { rejected } \\
H_{0} \text { accepted }\end{array}$ & 0.7571 \\
\hline KELY & $\begin{array}{l}0.9725 \\
0.9742 \\
0.9951\end{array}$ & $\begin{array}{l}\boldsymbol{H}_{\mathbf{0}} \text { rejected } \\
\boldsymbol{H}_{\mathbf{0}} \text { rejected } \\
H_{0} \text { accepted }\end{array}$ & $\begin{array}{l}0.9996 \\
0.9904\end{array}$ & $\begin{array}{l}H_{0} \text { accepted } \\
\boldsymbol{H}_{\mathbf{0}} \text { rejected }\end{array}$ & 0.9965 \\
\hline KIRU & $\begin{array}{l}0.9950 \\
0.9926 \\
0.9927\end{array}$ & $\begin{array}{l}H_{0} \text { accepted } \\
H_{0} \text { accepted } \\
H_{0} \text { accepted }\end{array}$ & $\begin{array}{l}0.9937 \\
0.9961\end{array}$ & $\begin{array}{l}H_{0} \text { accepted } \\
\boldsymbol{H}_{\mathbf{0}} \text { rejected }\end{array}$ & 0.9926 \\
\hline KOUR & $\begin{array}{l}0.9956 \\
0.9913 \\
0.9211\end{array}$ & $\begin{array}{l}H_{0} \text { accepted } \\
\boldsymbol{H}_{0} \text { rejected } \\
\boldsymbol{H}_{\mathbf{0}} \text { rejected }\end{array}$ & $\begin{array}{l}0.9914 \\
0.9886\end{array}$ & $\begin{array}{l}H_{0} \text { rejected } \\
H_{0} \text { rejected }\end{array}$ & 0.9956 \\
\hline POL2 & $\begin{array}{l}0.9978 \\
0.9963 \\
0.9981\end{array}$ & $\begin{array}{l}H_{0} \text { rejected } \\
H_{0} \text { rejected } \\
H_{0} \text { rejected } \\
\end{array}$ & $\begin{array}{l}0.9986 \\
0.9985\end{array}$ & $\frac{\boldsymbol{H}_{\mathbf{0}} \text { rejected }}{H_{0} \text { accepted }}$ & 0.9985 \\
\hline TOW2 & $\begin{array}{l}0.9675 \\
0.9995 \\
0.9991\end{array}$ & $\begin{array}{c}H_{0} \text { rejected } \\
H_{0} \text { rejected } \\
H_{0} \text { rejected }\end{array}$ & $\begin{array}{l}0.9933 \\
0.9995\end{array}$ & $\begin{array}{c}\boldsymbol{H}_{\mathbf{0}} \text { rejected } \\
H_{0} \text { accepted }\end{array}$ & 0.9996 \\
\hline TRAK & $\begin{array}{l}0.9968 \\
0.9917 \\
0.9753\end{array}$ & $\begin{array}{l}H_{0} \text { accepted } \\
\boldsymbol{H}_{\mathbf{0}} \text { rejected } \\
\boldsymbol{H}_{\mathbf{0}} \text { rejected }\end{array}$ & $\begin{array}{l}0.9971 \\
0.9852\end{array}$ & $\begin{array}{l}H_{0} \text { rejected } \\
H_{0} \text { rejected }\end{array}$ & 0.9945 \\
\hline USUD & $\begin{array}{l}0.9429 \\
0.9698 \\
0.9704\end{array}$ & $\begin{array}{l}H_{0} \text { accepted } \\
H_{0} \text { accepted } \\
\boldsymbol{H}_{\mathbf{0}} \text { rejected } \\
\end{array}$ & $\begin{array}{l}0.9489 \\
0.9735\end{array}$ & $\begin{array}{l}H_{0} \text { accepted } \\
H_{0} \text { accepted }\end{array}$ & 0.9667 \\
\hline VILL & $\begin{array}{l}0.9937 \\
0.9954 \\
0.9977\end{array}$ & $\begin{array}{l}H_{0} \text { rejected } \\
H_{0} \text { rejected } \\
H_{0} \text { rejected }\end{array}$ & $\begin{array}{l}0.9977 \\
0.9982\end{array}$ & $\begin{array}{c}\boldsymbol{H}_{\mathbf{0}} \text { rejected } \\
H_{0} \text { accepted }\end{array}$ & 0.9988 \\
\hline YELL & $\begin{array}{l}0.9928 \\
0.9774 \\
0.9944\end{array}$ & $\begin{array}{l}H_{0} \text { accepted } \\
\boldsymbol{H}_{\mathbf{0}} \text { rejected } \\
H_{0} \text { accepted }\end{array}$ & $\begin{array}{l}0.9954 \\
0.9899\end{array}$ & $\frac{\boldsymbol{H}_{\mathbf{0}} \text { rejected }}{H_{0} \text { accepted }}$ & 0.9944 \\
\hline
\end{tabular}

$R^{2}$ values indicating how well the solutions of shorter sessions fit to the mathematical models used. These constitute the model given in Eq. (2) for the horizontal components and the model given in Eq. (4) for the vertical component. In the final column of each table, we also provide the $R^{2}$ values of the solutions derived from $24 \mathrm{~h}$ sessions.

In the tables, if $H_{0}$ is indicated as accepted this means that the deformation rate (i.e., the velocity value) from the solutions of shorter sessions does not significantly differ from that of the $24 \mathrm{~h}$ solution. The bold-faced rejected $H_{0}$ means $\sigma_{0}^{2}$ from the least squares analysis of shorter sessions signif-
Table 3. Hypothesis testing results for longitude: rejections indicated in bold-faced letters are related to an $F$ test; rejections indicated in underlined bold-faced letters are from Student's $t$ test; the stations with $R^{2}$ values smaller than 0.99 are not used in the evaluation.

\begin{tabular}{|c|c|c|c|c|c|}
\hline Station & $R^{2}$ & $\begin{array}{l}8 \mathrm{~h} \\
\text { Test result }\end{array}$ & $R^{2}$ & $\begin{array}{l}12 \mathrm{~h} \\
\text { Test result }\end{array}$ & $\begin{array}{l}24 \mathrm{~h} \\
R^{2}\end{array}$ \\
\hline ANKR & $\begin{array}{l}0.7359 \\
0.5785 \\
0.6401\end{array}$ & $\begin{array}{l}\boldsymbol{H}_{\mathbf{0}} \text { rejected } \\
H_{0} \text { accepted } \\
\boldsymbol{H}_{\mathbf{0}} \text { rejected }\end{array}$ & $\begin{array}{l}0.4727 \\
0.7120\end{array}$ & $\begin{array}{l}H_{0} \text { accepted } \\
H_{0} \text { accepted }\end{array}$ & 0.6704 \\
\hline AREQ & $\begin{array}{l}0.9964 \\
0.9971 \\
0.9961\end{array}$ & $\begin{array}{l}H_{0} \text { accepted } \\
H_{0} \text { accepted } \\
H_{0} \text { accepted }\end{array}$ & $\begin{array}{l}0.9964 \\
0.9965\end{array}$ & $\begin{array}{c}H_{0} \text { accepted } \\
H_{0} \text { accepted }\end{array}$ & 0.9968 \\
\hline DAV1 & $\begin{array}{l}0.6495 \\
0.5418 \\
0.7756\end{array}$ & $\begin{array}{l}\boldsymbol{H}_{\mathbf{0}} \text { rejected } \\
\boldsymbol{H}_{\mathbf{0}} \text { rejected } \\
H_{0} \text { accepted }\end{array}$ & $\begin{array}{l}0.6735 \\
0.8527\end{array}$ & $\begin{array}{l}H_{0} \text { accepted } \\
H_{0} \text { accepted }\end{array}$ & 0.8075 \\
\hline GUAM & $\begin{array}{l}0.6150 \\
0.9306 \\
0.9096\end{array}$ & $\begin{array}{l}\boldsymbol{H}_{\mathbf{0}} \text { rejected } \\
\boldsymbol{H}_{\mathbf{0}} \text { rejected } \\
H_{0} \text { accepted }\end{array}$ & $\begin{array}{l}0.8530 \\
0.9083\end{array}$ & $\begin{array}{l}H_{0} \text { accepted } \\
H_{0} \text { accepted }\end{array}$ & 0.9444 \\
\hline KELY & $\begin{array}{l}0.9873 \\
0.9566 \\
0.9963\end{array}$ & $\begin{array}{l}H_{0} \text { rejected } \\
H_{0} \text { rejected } \\
H_{0} \text { rejected } \\
\end{array}$ & $\begin{array}{l}0.9935 \\
0.9941\end{array}$ & $\begin{array}{l}H_{0} \text { rejected } \\
H_{0} \text { rejected }\end{array}$ & 0.9973 \\
\hline KIRU & $\begin{array}{l}0.9918 \\
0.9890 \\
0.9942\end{array}$ & $\begin{array}{l}\boldsymbol{H}_{\mathbf{0}} \text { rejected } \\
\boldsymbol{H}_{\mathbf{0}} \text { rejected } \\
H_{0} \text { accepted }\end{array}$ & $\begin{array}{l}0.9946 \\
0.9929\end{array}$ & $\frac{H_{0} \text { rejected }}{H_{0} \text { rejected }}$ & 0.9954 \\
\hline KOUR & $\begin{array}{l}0.5840 \\
0.7160 \\
0.6112\end{array}$ & $\begin{array}{l}H_{0} \text { rejected } \\
H_{0} \text { rejected } \\
H_{0} \text { rejected }\end{array}$ & $\begin{array}{l}0.8820 \\
0.6419\end{array}$ & $\begin{array}{l}H_{0} \text { accepted } \\
H_{0} \text { accepted }\end{array}$ & 0.8581 \\
\hline POL2 & $\begin{array}{l}0.9792 \\
0.9686 \\
0.9730\end{array}$ & $\begin{array}{l}H_{0} \text { accepted } \\
H_{0} \text { accepted } \\
\boldsymbol{H}_{\mathbf{0}} \text { rejected } \\
\end{array}$ & $\begin{array}{l}0.9757 \\
0.9733\end{array}$ & $\begin{array}{l}H_{0} \text { accepted } \\
\boldsymbol{H}_{\mathbf{0}} \text { rejected } \\
\end{array}$ & 0.9833 \\
\hline TOW2 & $\begin{array}{l}0.9600 \\
0.9790 \\
0.9964\end{array}$ & $\begin{array}{l}H_{0} \text { rejected } \\
H_{0} \text { rejected } \\
H_{0} \text { rejected } \\
\end{array}$ & $\begin{array}{l}0.9901 \\
0.9968\end{array}$ & $\begin{array}{l}H_{0} \text { rejected } \\
H_{0} \text { rejected } \\
\end{array}$ & 0.9973 \\
\hline TRAK & $\begin{array}{l}0.9925 \\
0.9902 \\
0.9903\end{array}$ & $\begin{array}{l}H_{0} \text { rejected } \\
H_{0} \text { rejected } \\
H_{0} \text { rejected }\end{array}$ & $\begin{array}{l}0.9914 \\
0.9960\end{array}$ & $\begin{array}{c}\boldsymbol{H}_{\mathbf{0}} \text { rejected } \\
H_{0} \text { accepted }\end{array}$ & 0.9972 \\
\hline USUD & $\begin{array}{l}0.0049 \\
0.1218 \\
0.0282\end{array}$ & $\begin{array}{l}\boldsymbol{H}_{\mathbf{0}} \text { rejected } \\
H_{0} \text { accepted } \\
\boldsymbol{H}_{\mathbf{0}} \text { rejected }\end{array}$ & $\begin{array}{l}0.0001 \\
0.0807\end{array}$ & $\begin{array}{l}H_{0} \text { accepted } \\
H_{0} \text { accepted }\end{array}$ & 0.0484 \\
\hline VILL & $\begin{array}{l}0.9883 \\
0.9943 \\
0.9957\end{array}$ & $\begin{array}{l}H_{0} \text { rejected } \\
H_{0} \text { rejected } \\
H_{0} \text { rejected }\end{array}$ & $\begin{array}{l}0.9977 \\
0.9959\end{array}$ & $\begin{array}{l}H_{0} \text { accepted } \\
H_{0} \text { accepted }\end{array}$ & 0.9977 \\
\hline YELL & $\begin{array}{l}0.9859 \\
0.9948 \\
0.9966\end{array}$ & $\begin{array}{l}\boldsymbol{H}_{\mathbf{0}} \text { rejected } \\
\boldsymbol{H}_{\mathbf{0}} \text { rejected } \\
H_{0} \text { accepted }\end{array}$ & $\begin{array}{l}0.9918 \\
0.9974\end{array}$ & $\begin{array}{c}\boldsymbol{H}_{\mathbf{0}} \text { rejected } \\
H_{0} \text { accepted }\end{array}$ & 0.9977 \\
\hline
\end{tabular}

icantly differs from that of the $24 \mathrm{~h}$ solution according to an $F$ test with $\alpha=0.05$, whereas bold-faced underlined rejected $H_{0}$ means the deformation rate from the shorter sessions significantly differs from that of the $24 \mathrm{~h}$ solution according to a $t$ test.

Note that Table 4 contains results from only five of the GPS stations we used. This is because we omitted the stations with $R^{2}$ values less than 0.65 . This will be discussed later on in this section as we interpret the results from the vertical component. 
Table 4. Hypothesis testing results for ellipsoidal height: rejections indicated in bold-faced letters are related to an $F$ test; rejections indicated in underlined bold-faced letters are from Student's $t$ test; the stations with $R^{2}$ values smaller than 0.90 are not used in the evaluation.

\begin{tabular}{|c|c|c|c|c|c|}
\hline Station & $R^{2}$ & $\begin{array}{l}8 \mathrm{~h} \\
\text { Test result }\end{array}$ & $R^{2}$ & $\begin{array}{l}12 \mathrm{~h} \\
\text { Test result }\end{array}$ & $\begin{array}{l}24 \mathrm{~h} \\
R^{2}\end{array}$ \\
\hline ANKR & $\begin{array}{l}0.7067 \\
0.5270 \\
0.6300\end{array}$ & $\begin{array}{l}H_{0} \text { rejected } \\
H_{0} \text { rejected } \\
H_{0} \text { rejected }\end{array}$ & $\begin{array}{l}0.7065 \\
0.6707\end{array}$ & $\begin{array}{l}\boldsymbol{H}_{\mathbf{0}} \text { rejected } \\
H_{0} \text { accepted }\end{array}$ & 0.7143 \\
\hline AREQ & $\begin{array}{l}0.4115 \\
0.5412 \\
0.3608\end{array}$ & $\begin{array}{l}\boldsymbol{H}_{\mathbf{0}} \text { rejected } \\
H_{0} \text { accepted } \\
\boldsymbol{H}_{\mathbf{0}} \text { rejected }\end{array}$ & $\begin{array}{l}0.5880 \\
0.4345\end{array}$ & $\frac{H_{0} \text { rejected }}{H_{0} \text { rejected }}$ & 0.6472 \\
\hline KELY & $\begin{array}{l}0.9054 \\
0.8817 \\
0.8831\end{array}$ & $\begin{array}{l}H_{0} \text { rejected } \\
H_{0} \text { rejected } \\
H_{0} \text { rejected }\end{array}$ & $\begin{array}{l}0.9126 \\
0.9181\end{array}$ & $\begin{array}{l}H_{0} \text { rejected } \\
H_{0} \text { rejected }\end{array}$ & 0.9331 \\
\hline KIRU & $\begin{array}{l}0.8602 \\
0.8739 \\
0.7772\end{array}$ & $\begin{array}{c}H_{0} \text { rejected } \\
H_{0} \text { rejected } \\
H_{0} \text { rejected }\end{array}$ & $\begin{array}{l}0.8821 \\
0.8727\end{array}$ & $\begin{array}{c}H_{0} \text { rejected } \\
H_{0} \text { rejected }\end{array}$ & 0.9091 \\
\hline YELL & $\begin{array}{l}0.8648 \\
0.8627 \\
0.8873\end{array}$ & $\frac{H_{0} \text { rejected }}{H_{0} \text { rejected }}$ & $\begin{array}{l}0.8923 \\
0.9108\end{array}$ & $\begin{array}{c}H_{0} \text { rejected } \\
H_{0} \text { rejected }\end{array}$ & 0.9171 \\
\hline
\end{tabular}

As expected, both deformation rates and $R^{2}$ values from $12 \mathrm{~h}$ solutions for latitude and longitude components better approximate to those of the $24 \mathrm{~h}$ solutions than the vertical component. This can be clearly observed from Table 4 . There the differences between the related $R^{2}$ values can be distinguished clearly.

Note that $R^{2}$ values for the horizontal components are usually at 0.95 or over. This is due to the fact that the horizontal motion is in general related to the tectonic motion and shows clear linearity. Thus $R^{2}$ values which are close to 1 are the principal indicator of this. For the assessment of horizontal components latitude and longitude we used $R^{2}$ values greater than 0.99. The $R^{2}$ values are shown in Tables 2 and 3 . If one evaluates the hypothesis testing results in Tables 2 and 3 beyond the stations with $R^{2}$ values smaller than $99 \%$ they will note that only $40 \%$ of the latitudinal and $43 \%$ of the longitudinal coordinate velocities (i.e., the deformation rates or estimated $\hat{a}$ values from Eq. 2) from $12 \mathrm{~h}$ solutions are comparable to those of the $24 \mathrm{~h}$ solutions. The picture is much worse for the $12 \mathrm{~h}$ vertical coordinate velocities. The results in regard to the height component from the new sampling and the model given with Eq. (4) are presented in Table 4. In Table 4, only the stations with $R^{2}$ values greater than 0.65 , namely ANKR, AREQ, KELY, KIRU and YELL, are included. The $R^{2}$ values for the rest of the stations ranged from 0.04 to 0.39 and therefore were not included in the table. Obviously, our model given with Eq. (4) included some unmodeled effects for eight of the remaining stations. However, for the assessments, we only used the stations with $R^{2}$ values greater than 0.90 , and these stations are also shown in Table 4 . The analysis from this evaluation revealed that none of the estimated vertical velocities from $12 \mathrm{~h}$ sessions are comparable to those of the $24 \mathrm{~h}$ solutions.

In fact, 11 out of 13 GPS stations include significant annual components in the height coordinate. However, only five of the stations are affected by the semiannual component. This has been confirmed by applying Student's two-sided $t$ test with $\alpha=0.05$ to the seasonal constituents $c$ and $d$ in Eq. (4). Note that the stations with small $R^{2}$ values usually correspond to the ones between -40 and $+40^{\circ}$ latitudes. We know that the magnetic field of the earth has an adverse effect on the repeated GPS solutions at equatorial regions (Kedar et al., 2003). Usually the solutions from the vertical component are affected. Sanli and Tekic (2010) also noted this effect on GIPSY processing solutions related to the vertical component.

Eight hour solutions obviously show poorer results. Only $37 \%$ of latitudinal velocities and $21 \%$ of the longitudinal velocities are significantly comparable to those of the $24 \mathrm{~h}$ solutions (Tables 2 and 3). The fact that longitudinal estimates are worse than latitudinal estimates could be ascribed to the ambiguity resolution. At the time of processing version 5.0 of the APPS software was available. However, GIPSY ambiguity resolution released with version 6.0. Bertiger et al. (2010) showed the improvement on the longitudinal component after applying ambiguity resolution in the processing. Eight hour vertical velocity estimates are much worse than those of the horizontal velocity estimates. According to this, all of the estimated velocities from $8 \mathrm{~h}$ sessions significantly differ from those of the $24 \mathrm{~h}$ solutions (Table 4 ).

One can infer from the above discussion that the accuracy of the vertical velocities is affected much worse compared to those of the horizontal components. In addition, if one extends the observing session from 8 to $12 \mathrm{~h}$, the accuracy is improved. The reason we prefer to analyze 8 and $12 \mathrm{~h}$ is that those session durations approximate the lower and the upper limits to the ones usually applied in practice. In other words, the user prefers about $10 \mathrm{~h}$ on average as the observation session for the repeated GPS measurements, and they usually desire to take advantage of the daylight.

The ideal session length for a GPS campaign is obviously $24 \mathrm{~h}$. This is mainly due to the fact that satellite constellation repeats in $24 \mathrm{~h}$ and hence all the systematic effects such as multipath and mapping-function errors tend to average out (Blewitt, 1993). If this cannot be managed, one needs to collect GPS measurements at least for $18 \mathrm{~h}$ in order to eliminate the effect of the semi-diurnal $\left(M_{2}\right)$ ocean tide loading, especially in the places where the tidal effect is severe. However, as implied above, from the view of practical and security considerations many users who carry out campaign measurements prefer to take advantage of daylight, and hence this limits the observation session to $8-12 \mathrm{~h}$. If this is the case, repeated GPS solutions from campaign measurements are biased in the places where ocean tide loading is effective or in the places where high post-glacial rebound/glacial isostatic adjustment effect is seen (Sanli and Blewitt, 2001). 
Table 5. Comparison of $R^{2}$ values from annual and monthly GPS campaigns for the height component using $24 \mathrm{~h}$ solutions. The improved $R^{2}$ values from monthly analysis are shown with bold numbers.

\begin{tabular}{lrr}
\hline Station & $\begin{array}{r}\text { Annual } \\
R^{2}\end{array}$ & $\begin{array}{r}\text { Monthly } \\
R^{2}\end{array}$ \\
\hline ANKR & 0.2181 & $\mathbf{0 . 7 1 4 3}$ \\
AREQ & 0.0060 & $\mathbf{0 . 6 4 7 2}$ \\
DAV1 & 0.6836 & 0.0794 \\
GUAM & 0.1769 & 0.1094 \\
KELY & 0.1078 & $\mathbf{0 . 9 3 3 1}$ \\
KIRU & 0.7632 & $\mathbf{0 . 9 0 9 1}$ \\
KOUR & 0.4610 & 0.0939 \\
POL2 & 0.0847 & 0.3900 \\
TOW2 & 0.0507 & 0.0453 \\
TRAK & 0.4061 & 0.2858 \\
USUD & 0.2887 & 0.0954 \\
VILL & 0.1766 & 0.0715 \\
YELL & 0.5918 & $\mathbf{0 . 9 1 7 1}$ \\
\hline
\end{tabular}

Obviously there is no need to mention the places in which subsidence or uplifts occur due to earthquakes, tsunamis or other natural hazards such as landslides and erosions.

$R^{2}$ values for the height component from monthly and annual analyses showed differences. After densifying the height time series including monthly GPS data, the modeling usually became stronger for the mid- or higher-latitude northern hemispheric stations with growing $R^{2}$ values whereas it got worse for low latitude stations. Interestingly, the $R^{2}$ value of the station DAV1 from the South Pole (i.e., Antarctica) decreased. We checked the continuous height time series from SOPAC and noted that the solutions (i.e., the height estimates) prior to 2004 are very noisy, and this might affect the velocities estimated from annually spanned GPS solutions. Table 5 is designed to compare $R^{2}$ values from the annual and monthly campaigns. The evaluation is only given for $24 \mathrm{~h}$ solutions.

Comparison of RMSDs and RMSEEs is given in Tables 6 through 8 . In the tables, under the column RMSD, root mean square differences between $24 \mathrm{~h}$ solutions and the solutions from shorter data spans, such as 8 and $24 \mathrm{~h}$, are represented according to Eq. (5). The RMSEE column shows root mean square error of estimated coordinates for 8 and $12 \mathrm{~h}$ solutions according to Eqs. (6) or (7). The solutions showing agreement between the two measures are presented in bold-faced letters. The comparisons are made for all three GPS baselines latitude, longitude and ellipsoidal height in Tables 6 through 8 .

If we accept the RMSDs as the truth and compare RMSEEs with those, $36 \%$ of $8 \mathrm{~h}$ solutions and $38 \%$ of the $12 \mathrm{~h}$ solutions show agreement around $1 \mathrm{~mm}$ for the latitudinal component (Table 6). These are indicated with bold-faced numbers in the tables. Note that these results are comparable
Table 6. Testing whether RMSEEs from individual latitudinal short session regression models are identical to RMSDs formed using $24 \mathrm{~h}$ solutions as the truth ( $1 \mathrm{~mm}$ threshold is used). The identical solutions are shown with bold numbers.

\begin{tabular}{|c|c|c|c|c|}
\hline \multirow[t]{2}{*}{ Station } & \multicolumn{2}{|c|}{$8 \mathrm{~h}$} & \multicolumn{2}{|c|}{$12 \mathrm{~h}$} \\
\hline & $\begin{array}{l}\text { RMSD } \\
(\mathrm{m})\end{array}$ & $\begin{array}{l}\text { RMSEE } \\
(\mathrm{m})\end{array}$ & $\begin{array}{l}\text { RMSD } \\
(\mathrm{m})\end{array}$ & $\begin{array}{l}\text { RMSEE } \\
(\mathrm{m})\end{array}$ \\
\hline \multirow[t]{3}{*}{ ANKR } & 0.0225 & 0.0136 & 0.0041 & 0.0038 \\
\hline & 0.0082 & 0.0030 & 0.0036 & 0.0116 \\
\hline & 0.0060 & 0.0085 & & \\
\hline \multirow[t]{3}{*}{ AREQ } & 0.0077 & 0.0072 & 0.0033 & 0.0070 \\
\hline & 0.0059 & 0.0099 & 0.0024 & 0.0087 \\
\hline & 0.0026 & 0.0083 & & \\
\hline \multirow[t]{3}{*}{ DAV1 } & 0.0178 & 0.0112 & 0.0059 & 0.0044 \\
\hline & 0.0065 & 0.0071 & 0.0063 & 0.0060 \\
\hline & 0.0053 & 0.0061 & & \\
\hline \multirow[t]{3}{*}{ GUAM } & 0.0107 & 0.0112 & 0.0073 & 0.0093 \\
\hline & 0.0068 & 0.0084 & 0.0056 & 0.0072 \\
\hline & 0.0071 & 0.0072 & & \\
\hline \multirow[t]{3}{*}{ KELY } & 0.0086 & 0.0086 & 0.0030 & 0.0031 \\
\hline & 0.0100 & 0.0091 & 0.0048 & 0.0054 \\
\hline & 0.0145 & 0.0131 & & \\
\hline \multirow[t]{3}{*}{ KIRU } & 0.0050 & 0.0047 & 0.0036 & 0.0053 \\
\hline & 0.0028 & 0.0057 & 0.0051 & 0.0041 \\
\hline & 0.0079 & 0.0056 & & \\
\hline \multirow[t]{3}{*}{ KOUR } & 0.0039 & 0.0039 & 0.0038 & 0.0054 \\
\hline & 0.0052 & 0.0052 & 0.0057 & 0.0061 \\
\hline & 0.0139 & 0.0154 & & \\
\hline \multirow[t]{3}{*}{ POL2 } & 0.0020 & 0.0036 & 0.0029 & 0.0040 \\
\hline & 0.0032 & 0.0046 & 0.0032 & 0.0039 \\
\hline & 0.0036 & 0.0037 & & \\
\hline \multirow[t]{3}{*}{ TOW2 } & 0.0049 & 0.0071 & 0.0161 & 0.0188 \\
\hline & 0.0076 & 0.0054 & 0.0041 & 0.0051 \\
\hline & 0.0057 & 0.0070 & & \\
\hline \multirow[t]{3}{*}{ TRAK } & 0.0053 & 0.0047 & 0.0064 & 0.0045 \\
\hline & 0.0087 & 0.0074 & 0.0054 & 0.0102 \\
\hline & 0.0078 & 0.0135 & & \\
\hline \multirow[t]{3}{*}{ USUD } & 0.0075 & 0.0107 & 0.0058 & 0.0100 \\
\hline & 0.0054 & 0.0077 & 0.0044 & 0.0073 \\
\hline & 0.0040 & 0.0074 & & \\
\hline \multirow[t]{3}{*}{ VILL } & 0.0074 & 0.0060 & 0.0090 & 0.0051 \\
\hline & 0.0051 & 0.0050 & 0.0073 & 0.0032 \\
\hline & 0.0041 & 0.0036 & & \\
\hline \multirow[t]{3}{*}{ YELL } & 0.0031 & 0.0043 & 0.0028 & 0.0035 \\
\hline & 0.0052 & 0.0076 & 0.0016 & 0.0050 \\
\hline & 0.0032 & 0.0038 & & \\
\hline
\end{tabular}

with those of the hypothesis testing results, in which $37 \%$ of velocities derived from $8 \mathrm{~h}$ solutions and $40 \%$ of the velocities derived from $12 \mathrm{~h}$ solutions were found to be statistically significant.

For the longitude component, $28 \%$ of $8 \mathrm{~h}$ and $38 \%$ of $12 \mathrm{~h}$ RMSEE values showed good agreement with RMSD values 
Table 7. Testing whether RMSEEs from individual longitudinal short session regression models are identical to RMSDs formed using $24 \mathrm{~h}$ solutions as the truth ( $1 \mathrm{~mm}$ threshold is used). The identical solutions are shown with bold numbers.

\begin{tabular}{|c|c|c|c|c|}
\hline \multirow[t]{2}{*}{ Station } & \multicolumn{2}{|c|}{$8 \mathrm{~h}$} & \multicolumn{2}{|c|}{$12 \mathrm{~h}$} \\
\hline & $\begin{array}{l}\text { RMSD } \\
(\mathrm{m})\end{array}$ & $\begin{array}{l}\text { RMSEE } \\
(\mathrm{m})\end{array}$ & $\begin{array}{l}\text { RMSD } \\
(\mathrm{m})\end{array}$ & $\begin{array}{l}\text { RMSEE } \\
(\mathrm{m})\end{array}$ \\
\hline \multirow[t]{3}{*}{ ANKR } & 0.0150 & 0.0145 & 0.0068 & 0.0046 \\
\hline & 0.0054 & 0.0043 & 0.0055 & 0.0040 \\
\hline & 0.0072 & 0.0067 & & \\
\hline \multirow[t]{3}{*}{ AREQ } & 0.0236 & 0.0140 & 0.0042 & 0.0131 \\
\hline & 0.0063 & 0.0111 & 0.0057 & 0.0148 \\
\hline & 0.0067 & 0.0138 & & \\
\hline \multirow[t]{3}{*}{ DAV1 } & 0.0086 & 0.0112 & 0.0066 & 0.0107 \\
\hline & 0.0101 & 0.0139 & 0.0064 & 0.0054 \\
\hline & 0.0088 & 0.0063 & & \\
\hline \multirow[t]{3}{*}{ GUAM } & 0.0198 & 0.0262 & 0.0089 & 0.0168 \\
\hline & 0.0161 & 0.0124 & 0.0094 & 0.0133 \\
\hline & 0.0113 & 0.0126 & & \\
\hline \multirow[t]{3}{*}{ KELY } & 0.0235 & 0.0100 & 0.0171 & 0.0070 \\
\hline & 0.0157 & 0.0178 & 0.0052 & 0.0064 \\
\hline & 0.0086 & 0.0052 & & \\
\hline \multirow[t]{3}{*}{ KIRU } & 0.0042 & 0.0065 & 0.0034 & 0.0052 \\
\hline & 0.0076 & 0.0072 & 0.0035 & 0.0059 \\
\hline & 0.0065 & 0.0053 & & \\
\hline \multirow[t]{3}{*}{ KOUR } & 0.0161 & 0.0166 & 0.0150 & 0.0080 \\
\hline & 0.0171 & 0.0154 & 0.0192 & 0.0194 \\
\hline & 0.0199 & 0.0210 & & \\
\hline \multirow[t]{3}{*}{ POL2 } & 0.0039 & 0.0059 & 0.0032 & 0.0047 \\
\hline & 0.0056 & 0.0075 & 0.0038 & 0.0047 \\
\hline & 0.0055 & 0.0053 & & \\
\hline \multirow[t]{3}{*}{ TOW2 } & 0.0059 & 0.0118 & 0.0083 & 0.0114 \\
\hline & 0.0141 & 0.0164 & 0.0094 & 0.0069 \\
\hline & 0.0140 & 0.0075 & & \\
\hline \multirow[t]{3}{*}{ TRAK } & 0.0080 & 0.0150 & 0.0080 & 0.0161 \\
\hline & 0.0147 & 0.0171 & 0.0108 & 0.0110 \\
\hline & 0.0181 & 0.0143 & & \\
\hline \multirow[t]{3}{*}{ USUD } & 0.0149 & 0.0116 & 0.0083 & 0.0116 \\
\hline & 0.0108 & 0.0089 & 0.0063 & 0.0068 \\
\hline & 0.0127 & 0.0061 & & \\
\hline \multirow[t]{3}{*}{ VILL } & 0.0080 & 0.0091 & 0.0040 & 0.0041 \\
\hline & 0.0063 & 0.0066 & 0.0050 & 0.0054 \\
\hline & 0.0044 & 0.0056 & & \\
\hline \multirow{3}{*}{ YELL } & 0.0070 & 0.0088 & 0.0056 & 0.0068 \\
\hline & 0.0058 & 0.0054 & 0.0042 & $\mathbf{0 . 0 0 3 7}$ \\
\hline & 0.0050 & 0.0043 & & \\
\hline
\end{tabular}

(Table 7). These are also comparable to those of the hypothesis testing results, in which only $24 \%$ of the velocities derived from $8 \mathrm{~h}$ and $43 \%$ of the velocities derived from $12 \mathrm{~h}$ solutions were found to be useful.

For the vertical component, only one RMSEE value, which corresponds to about $3 \%$ of the total solutions, was found
Table 8. Testing whether RMSEEs from individual vertical short session regression models are identical to RMSDs formed using $24 \mathrm{~h}$ solutions as the truth ( $1 \mathrm{~mm}$ threshold is used). The identical solutions are shown with bold numbers.

\begin{tabular}{|c|c|c|c|c|}
\hline \multirow[t]{2}{*}{ Station } & \multicolumn{2}{|c|}{$8 \mathrm{~h}$} & \multicolumn{2}{|c|}{$12 \mathrm{~h}$} \\
\hline & $\begin{array}{l}\text { RMSD } \\
(\mathrm{m})\end{array}$ & $\begin{array}{l}\text { RMSEE } \\
(\mathrm{m})\end{array}$ & $\begin{array}{l}\text { RMSD } \\
(\mathrm{m})\end{array}$ & $\begin{array}{l}\text { RMSEE } \\
(\mathrm{m})\end{array}$ \\
\hline \multirow[t]{3}{*}{ ANKR } & 0.0067 & 0.0196 & 0.0044 & 0.0202 \\
\hline & 0.0097 & 0.0223 & 0.0049 & 0.0203 \\
\hline & 0.0075 & 0.0206 & & \\
\hline \multirow[t]{3}{*}{ AREQ } & 0.0116 & 0.0181 & 0.0066 & 0.0149 \\
\hline & 0.0071 & 0.0139 & 0.0095 & 0.0150 \\
\hline & 0.0145 & 0.0180 & & \\
\hline \multirow[t]{3}{*}{ DAV1 } & 0.0063 & 0.0103 & 0.0058 & 0.0100 \\
\hline & 0.0088 & 0.0123 & 0.0052 & 0.0102 \\
\hline & 0.0080 & 0.0121 & & \\
\hline \multirow[t]{3}{*}{ GUAM } & 0.0338 & 0.0387 & 0.0166 & 0.0241 \\
\hline & 0.0184 & 0.0186 & 0.0166 & 0.0241 \\
\hline & 0.0171 & 0.0208 & & \\
\hline \multirow[t]{3}{*}{ KELY } & 0.0076 & 0.0234 & 0.0050 & 0.0230 \\
\hline & 0.0070 & 0.0242 & 0.0052 & 0.0231 \\
\hline & 0.0098 & 0.0238 & & \\
\hline \multirow[t]{3}{*}{ KIRU } & 0.0092 & 0.0148 & 0.0055 & 0.0146 \\
\hline & 0.0093 & 0.0175 & 0.0086 & 0.0167 \\
\hline & 0.0159 & 0.0210 & & \\
\hline \multirow[t]{3}{*}{ KOUR } & 0.0192 & 0.0393 & 0.0136 & 0.0393 \\
\hline & 0.0233 & 0.0431 & 0.0240 & 0.0397 \\
\hline & 0.0278 & 0.0430 & & \\
\hline \multirow[t]{3}{*}{ POL2 } & 0.0077 & 0.0106 & 0.0058 & 0.0108 \\
\hline & 0.0067 & 0.0094 & 0.0040 & 0.0082 \\
\hline & 0.0063 & 0.0086 & & \\
\hline \multirow[t]{3}{*}{ TOW2 } & 0.0120 & 0.0149 & 0.0076 & 0.0111 \\
\hline & 0.0082 & 0.0109 & 0.0063 & 0.0093 \\
\hline & 0.0085 & 0.0107 & & \\
\hline \multirow[t]{3}{*}{ TRAK } & 0.0107 & 0.0146 & 0.0054 & 0.0098 \\
\hline & 0.0113 & 0.0133 & 0.0066 & 0.0091 \\
\hline & 0.0157 & 0.0171 & & \\
\hline \multirow[t]{3}{*}{ USUD } & 0.0120 & 0.0189 & 0.0091 & 0.0173 \\
\hline & 0.0123 & 0.0175 & 0.0084 & 0.0146 \\
\hline & 0.0112 & 0.0154 & & \\
\hline \multirow[t]{3}{*}{ VILL } & 0.0078 & 0.0105 & 0.0056 & 0.0104 \\
\hline & 0.0113 & 0.0155 & 0.0074 & 0.0124 \\
\hline & 0.0110 & 0.0153 & & \\
\hline \multirow[t]{3}{*}{ YELL } & 0.0071 & 0.0113 & 0.0054 & 0.0103 \\
\hline & 0.0085 & 0.0124 & 0.0042 & 0.0098 \\
\hline & 0.0054 & 0.0112 & & \\
\hline
\end{tabular}

to be comparable to the corresponding RMSD value. This result is also comparable to the hypothesis testing result for the height component, in which none of the vertical velocities were found to be useful from short observation sessions. 


\section{Conclusions}

In this article, we assessed the accuracy of velocities from repeated GPS measurements. GPS experiments still reporting the results from repeated measurements motivated us to carry out this study. Continuous data of a global network of IGS stations were used to perform the evaluations. This helped us to comprehend the regional differences. Since, in practice, repeated GPS measurements are typically carried out in sessions of about $10 \mathrm{~h}$, we studied observation sessions of 8 and $12 \mathrm{~h}$. Based on the above information our conclusions are as follows.

Accuracy loss for the velocities occurs when using repeated GPS measurements from short sessions. This is because one does not perform ideal $24 \mathrm{~h}$ observations. $18 \mathrm{~h}$ should be sufficient considering that the effect of ocean tide loading can only be eliminated over 1.5 times the length of the semi-diurnal $\mathrm{M}_{2}$ tide. However, in practice the advantage of daylight is preferred. This limits the measurement period typically to around $10 \mathrm{~h}$. Taking into account various possible problems that could occur during the field campaign, the observing session duration might even become shorter. $\mathrm{Ob}$ viously this would lead to poorer accuracies.

We used two different statistical methods to assess the quality of our results. First we assessed whether or not the estimated velocities from short sessions (i.e., 8 and $12 \mathrm{~h}$ ) are comparable to those of $24 \mathrm{~h}$ sessions referring to statistical hypothesis testing. Second, we evaluated whether the accuracy of the regressions (i.e., RMSEE) from shorter sessions are identical to RMSDs formed holding $24 \mathrm{~h}$ solutions as the truth. The comparison of the two led to an independent accuracy evaluation. In both approaches, we assumed $24 \mathrm{~h}$ solutions produce true values and deviation from $24 \mathrm{~h}$ solutions should result in accuracy losses. Higher $R^{2}$ values (better model fits) from $24 \mathrm{~h}$ data confirmed this assumption. The results from both methods helped us to quantify the accuracy loss when not using $24 \mathrm{~h}$ observations.

Our first major conclusion is that the vertical rates produced from repeated GPS campaigns are severely affected. In addition, considering only the annual and the semiannual periodicities for the vertical component was not sufficient to capture the true vertical signal for most of the stations. In 8 out of 13 stations other influences dominated, resulting in greater modeling errors. We noticed low-frequency hidden periodicities in the vertical component; however, these need to be revealed by adopting sophisticated time series analysis procedures in the future. The above-mentioned first method revealed that none of the velocities from shorter GPS sessions were useful for the height component. The second method gave almost a similar result in which only $3 \%$ (i.e., one of the solutions) of the RMSEEs were found to be comparable to the RMSDs. This shows us that the results derived from campaign GPS data using $8-12 \mathrm{~h}$ observation sessions are not useful for height determination.
Our horizontal velocity evaluations based on the statistical methods highlighted above showed pretty close results in which only about $30 \%$ of $8 \mathrm{~h}$ and $40 \%$ of $12 \mathrm{~h}$ solutions were found to be useful. Increasing observation duration from 8 to $12 \mathrm{~h}$ did not show much accuracy improvement, i.e., as much as $10 \%$; however, $60-70 \%$ accuracy loss in the case $24 \mathrm{~h}$ data is not really credible. Many research groups considered that at least the horizontal components would not be affected when using repeated GPS campaigns; however, the results of this study contradict with such ideas.

Obviously, these results are essentially related to GIPSY PPP methodology, in which minimum $6 \mathrm{~h}$ data are requested for a solution as stated in the literature. However, this is also related to conventional relative positioning (RP) results where regional or global studies are concerned. Many crustal deformation experiments to date were monitored using RP connecting to IGS reference stations which are located on stable tectonic plates hundreds or thousands of kilometers away from study areas.

Mostly the GPS stations from the lower or the equatorial belt suffer from modeling errors and hence accuracy loss, especially for the vertical component. One known error source acting on repeated GPS campaigns and dominating at these regions is ionospheric disturbances due to the magnetic field of the earth.

Acknowledgements. The data of this study were obtained from the IGS through SOPAC archives. We express our gratitude to both institutions for their excellent service in distributing the GPS data and the other products. Processing of the data was performed using web-based GIPSY (i.e., APPS). We would like to thank NASA for the excellent processing facility that could be used worldwide research community. Last but not least we would like to thank three anonymous reviewers and the editor David Keefer for their constructive reviews.

Edited by: O. Katz

Reviewed by: A. Dermanis and three anonymous referees

\section{References}

Altamimi, Z., Collilieux, X., Legrand, J., Garayt, B., and Boucher, C.: ITRF2005: A new release of the International Terrestrial Reference Frame based on time series of station positions and Earth Orientation Parameters, J. Geophys. Res., 112, B09401, doi:10.1029/2007JB004949, 2007.

Amiri-Simkooei, A. R., Tiberius, C. C. J. M., and Teunissen, P. J. G.: Assessment of noise in GPS coordinate time series: Methodology and results, J. Geophys. Res., 112, B07413, doi:10.1029/2006JB004913, 2007.

Ashurkov, S. V., San'kov, V. A., Miroshnichenko, A. I., Lukhnev, A. V., Sorokin, A. P., Serov, M. A., and Byzov, L. M.: GPS geodetic constraints on the kinematics of the Amurian Plate, Russ. Geol. Geophys., 52, 239-249, 2011.

Avallone, A., Marzario, M., Cirella, A., Piatanesi, A., Rovelli, A., Di Alessandro, C., D’Anastasio, E., D’Agostino, N., Giuliani, 
R., and Mattone, M.: Very high rate $(10 \mathrm{~Hz})$ GPS seismology for moderate-magnitude earthquakes: The case of the Mw 6.3 L'Aquila (central Italy) event, J. Geophys. Res., 116, B02305, doi:10.1029/2010JB007834, 2011.

Bertiger, W., Desai, S. D., Haines, B., Harvey, N., Moore, A. W., Owen, S., and Weiss, J. P.: Single receiver phase ambiguity resolution with GPS data, J Geodesy., 84, 327-337, 2010.

Blewitt, G.: Advances in Global Positioning System technology for geodynamics investigations, in: Contributions of Space Geodesy to Geodynamics: Technology, edited by: Smith, D. E. and Turcotte, D. L., American Geophysical Union (Geodynamics Series Vol. 25), Washington DC, 195-213, 1993.

Blewitt, G. and Lavalleé, D.: Effect of annual signals on geodetic velocity, J. Geophys. Res., 107, ETG 9-1-ETG 9-11, doi:10.1029/2001JB000570, 2002.

Blewitt, G., Kreemer, C., Hammond, W. C., Plag, H.-P., Stein, S., and Okal, E.: Rapid determination of earthquake magnitude using GPS for tsunami warning systems, Geophys. Res. Lett., 33, L11309, doi:10.1029/2006GL026145, 2006.

Blewitt, G., Hammond, W. C., Kreemer, C., Plag, H.-P., Stein, S., and Okal, E.: GPS for real-time earthquake source determination and tsunami warning systems, J. Geodesy., 83, 335-343, 2009.

Boehm, J., Niell, A., Tregoning, P., and Schuh, H.: Global Mapping Function (GMF): A new empirical mapping function based on numerical weather model data, Geophys. Res. Lett., 33, L07304, doi:10.1029/2005GL025546, 2006.

Brown, J. D.: Statistics Corner: Questions and answers about language testing statistics: The standard error vs. standard error of measurement?, Shiken: JALT Testing\&Evaluation SIG Newsletter, 3, 20-25, 1999.

Catalão, J., Nico, G., Hanssen, R., and Catita, C.: Merging GPS and Atmospherically Corrected InSAR Data to Map 3-D Terrain Displacement Velocity, IEEE T. Geosci. Remote, 49, 6, 23542360, 2011.

Crowell, B. W., Bock, Y., and Melgar, D.: Real-time inversion of GPS data for finite fault modeling and rapid hazard assessment, Geophys. Res. Lett., 39, L09305, doi:10.1029/2012GL051318, 2012.

Eckl, M. C., Snay, R. A., Soler, T., Cline, M. W., and Mader, G. L.: Accuracy of GPS-derived relative positions as a function of interstation distance and observing-session duration, J. Geodesy., 75, 633-640, 2001.

Elliot, J. L., Larsen, C. F., Freymueller, J. T., and Motyka, R.J .: Tectonic block motion and glacial isostatic adjustment in southeast Alaska and adjacent Canada constrained by GPS measurements, J. Geophys Res., 115, B09407, doi:10.1029/2009JB007139, 2010.

Firuzabadì, D. and King, R. W.: GPS precision as a function of session duration and reference frame using multi-point software, GPS Solut., 16, 191-196, 2012.

Genrich, J. F. and Bock, Y.: Instantaneous geodetic positioning with 10-50 Hz GPS measurements: Noise characteristics and implications for monitoring networks, J. Geophys. Res., 111, B03403, doi:10.1029/2005JB003617, 2006.

Hastaoglu, K. O. and Sanli, D. U.: Monitoring Koyulhisar Landslide Using Rapid Static GPS: A Strategy to Remove Biases from Vertical Velocities, Nat. Hazards, 58, 1275-1294, 2011.

Kedar, S., Hajj, G. A., Wilson, B. D., and Heflin, M. B.: The effect of the second order GPS ionospheric correc- tion on receiver positions, Geophys. Res. Lett., 30, 1829, doi:10.1029/2003GL017639, 2003.

Larson, K. M.: GPS seismology, J. Geodesy., 83, 227-233, 2009.

Mao, A., Harrison, C. G. A., and Dixon, T.: Noise in GPS coordinate time series, J. Geophys. Res., 104, 2797-2816, 1999.

Miranda, J. M., Navaro, A., Catalao, J., and Fernandes, R .M. S.: Surface displacement field at Terceira Island deduced from repeated GPS measurements, J. Volcanol. Geoth. Res., 217-218, $1-7,2012$.

Ozener, H., Dogru, A., and Acar, M.: Determination of the displacements along the Tuzla fault (Aegean region-Turkey): Preliminary results from GPS and precise leveling techniques, J. Geodyn., 67, 13-20, doi:10.1016/j.jog.2012.06.001, 2012.

Ozturk, D. and Sanli, D. U.: Accuracy of GPS Positioning from local to regional scales: A unified prediction model, Surv. Rev. 43, 79-589, 2011.

Pan, T. and Yin, Y.: The relationship between mean square differences and standard error of measurement: Comment on Barchard (2012), Psychol. Methods, 17, 309-311, 2012.

Petit, G. and Luzum, B. (Eds.): IERS Conventions (2010), IERS Technical Note 36, Int. Earth Rotation Serv., Paris, 179 pp., 2010.

Rontogianni, S.: Comparison of geodetic and seismic strain rates in Greece by using a uniform processing approach to campaign GPS measurements over the interval 1994-2000, J. Geodyn., 50, 381-399, 2010.

Sanli, D. U. and Blewitt, G.: Geocentric sea level trend using GPS and $>100-y r$ tide gauge record on a post glacial rebound nodal line, J. Geophys. Res., 106, 713-719, 2001.

Sanli, D. U. and Engin, C.: Accuracy of GPS positioning over regional scales, Surv. Rev., 41, 192-200, 2009.

Sanli, D. U. and Tekic, S.: Accuracy of GPS Precise Point Positioning: A Tool for GPS Accuracy Prediction, Saarbrücken: LAP Lambert Academic Publishing, 2010.

Santamaría-Gómez, A., Bouin, M-N., Collilieux, X., and Wöppelmann, G.: Correlated errors in GPS position time series: Implications for velocity estimates, J. Geophys. Res, 116, B01405, doi:10.1029/2010JB007701, 2011.

Soler, T., Michalak, P., Weston, N.D., Snay, R. A., and Foote, R. H.: Accuracy of OPUS solutions for 1- to 4-h observing sessions, GPS Solut., 10, 45-55, 2006.

Tran, D. T., Nguyena, T. Y., Duongb, C. C., Vya, Q. H., Zuchiewiczc, W., Cuonga, N. Q., and Nghiac, N. V.: Recent crustalmovements of northern Vietnam from GPS data, J. Geodyn., 69, 5-10, doi:10.1016/j.jog.2012.02.009, 2012.

Wang, G. and Soler, T.: OPUS for Horizontal SubcentimeterAccuracy Landslide Monitoring: Case Study in the Puerto Rico and Virgin Islands Region, J. Surv. Eng., 138, 143-153, 2012.

Williams, S. D. P.: The effect of coloured noise on the uncertainties of rates estimated from geodetic time series, J. Geodesy., 76, 483-494, 2003.

Williams, S. D. P., Bock, Y., Fang, P., Jamason, P., Nikolaidis, R. M., and Prawirodirdjo, L.: Error analysis of continuous GPS position time series, J. Geophys. Res., 109, B03412, doi:10.1029/2003JB002741, 2004.

Zumberge, J. F., Heflin, M. B., Jefferson, D. C., Watkins, M. M., and Webb, F. H.: Precise point positioning for the efficient and robust analysis of GPS data from large networks, J. Geophys. Res., 102, 5005-5017, 1997. 